\title{
The role of primary cilia in the pathophysiology of neural tube defects
}

\author{
Timothy W. Vogel, M.D., ${ }^{1}$ Calvin S. Carter, B.S., ${ }^{2}$ KingSley Abode-Iyamah, M.D., ${ }^{3}$ \\ Qihong Zhang, Ph.D., ${ }^{2}$ and Shenandoah Robinson, M.D. ${ }^{1}$
}

${ }^{\prime}$ Department of Neurosurgery, Children's Hospital Boston, Harvard Medical School, Boston, Massachusetts; and ${ }^{2}$ Graduate Program in Neuroscience, ${ }^{3}$ Department of Neurosurgery, University of Iowa, Iowa City, Iowa

\begin{abstract}
Neural tube defects (NTDs) are a set of disorders that occur from perturbation of normal neural development. They occur in open or closed forms anywhere along the craniospinal axis and often result from a complex interaction between environmental and genetic factors. One burgeoning area of genetics research is the effect of cilia signaling on the developing neural tube and how the disruption of primary cilia leads to the development of NTDs. Recent progress has implicated the hedgehog $(\mathrm{Hh})$, wingless-type integration site family (Wnt), and planar cell polarity (PCP) pathways in primary cilia as involved in normal neural tube patterning. A set of disorders involving cilia function, known as ciliopathies, offers insight into abnormal neural development. In this article, the authors discuss the common ciliopathies, such as Meckel-Gruber and Joubert syndromes, that are associated with NTDs, and review cilia-related signaling cascades responsible for mammalian neural tube development. Understanding the contribution of cilia in the formation of NTDs may provide greater insight into this common set of pediatric neurological disorders. (http://thejns.org/doi/abs/10.3171/2012.6.FOCUS12222)
\end{abstract}

$\begin{array}{lcccc}\text { KEY WORDS } & \text { cilia } & \bullet \quad \text { ciliopathy } & \bullet & \text { neural tube defect } \\ \text { sonic hedgehog } & \bullet & \text { development }\end{array}$

$\mathrm{N}$ EURAL tube disorders are a set of complex neural developmental abnormalities that occur in approximately 1 of 1500 births $^{4}$ and are the second most common birth defect..$^{32}$ Neural tube defects include both open and closed forms - with open forms resulting in failure of neural tube closure, seen in the cranial region with anencephaly and in the spinal region with spina bifida. Occasionally the entire craniospinal axis can be involved, such as in cases of craniorachischisis. Closed forms can present with more subtle phenotypic changes that are skin covered, including encephalocele, meningocele, and spina bifida occulta. ${ }^{47}$ These disorders are commonly seen in pediatric neurosurgical practices and often require intervention..$^{37}$

The pathogenesis of NTDs results from a complex contribution of genetic and environmental factors. The folic acid pathway ${ }^{5}$ has been well described in its contribution to the genesis of certain NTDs and significant in-

\footnotetext{
Abbreviations used in this paper: $\mathrm{APC}=$ adenomatous polyposis coli; Axin $=$ axis inhibitor; Dsh $=$ disheveled; Frz = frizzled; $\mathrm{Hh}=$ hedgehog; JBTS = Joubert syndrome; MKS = Meckel-Gruber syndrome; NTD = neural tube defect; $\mathrm{PCP}=$ planar cell polarity; PDGF $=$ platelet-derived growth factor; Ptch $=$ patched; Smo $=$ smooth ened; Wnt $=$ wingless-type integration site family.
}

ternational public health campaigns have helped increase awareness and prevention of NTDs. ${ }^{10,74}$ An understanding of the environmental factors is essential for prevention of these disorders..$^{51}$ In addition, genetics ${ }^{45,53}$ is emerging as an essential area to understanding the pathophysiology of NTDs. ${ }^{7}$ Limited size of patient cohorts has made identification of genes associated with NTDs difficult. As a result, investigators have relied on mouse models of NTDs ${ }^{25}$ to help identify pathways essential in normal neural tube development. The role of cilia ${ }^{40}$ in development is one such area where recent genetics research has improved our understanding of signaling cascades leading to NTDs. ${ }^{23}$

Cilia are evolutionarily conserved structures that are present on most vertebrate cells and are involved in essential cellular functions such as signaling. ${ }^{20}$ Cilia also play an essential role in patterning the developing nervous system ${ }^{23}$ by regulating neural stem cell migration, ${ }^{44}$ neural progenitor differentiation, ${ }^{62}$ and CSF movement. ${ }^{1,2,19}$ Disruption of the highly orchestrated processes involved in cilia function leads to CNS phenotypes ${ }^{76}$ seen in disorders known as ciliopathies. Ciliopathies, such as Meckel-Gruber syndrome ${ }^{13}$ (MKS, MIM 249000) and Joubert syndrome ${ }^{36}$ (JBTS, MIM 213300), are used to 
study a variety of systemic phenotypes and are increasingly associated with CNS abnormalities including cerebellar malformation, hydrocephalus, and NTDs. ${ }^{12,36}$

In the following sections we discuss the various forms of cilia and how the molecular pathways, proteins, and their respective signaling cascades pattern the developing neural tube. We also present the ciliopathies ${ }^{16} \mathrm{com}-$ monly associated with NTDs and illustrate how these disorders improve insight into the molecular underpinnings of neural tube formation.

\section{Cilia Structure}

Cilia are microtubule-based structures with a cytoskeleton called the axoneme (Fig. 1). Two major forms have been distinguished on the basis of ultrastructure: primary cilia and motile cilia. Primary cilia have a $9+$ 0 configuration, with 9 microtubule doublets arranged along their periphery. Motile cilia have a $9+2$ configuration; in addition to the 9 microtubule doublets of the primary cilia, motile cilia also have 2 central microtubules that are capable of generating movement through the interaction of dynein arms. ${ }^{28}$ Motile cilia are responsible for functions such as CSF movement ${ }^{22}$ and neural stem migration, ${ }^{44}$ and disruption in these structures leads to a variety of CNS phenotypes. ${ }^{76}$ In this paper, however, we will focus on primary cilia.

Primary cilia are immotile organelles that protrude

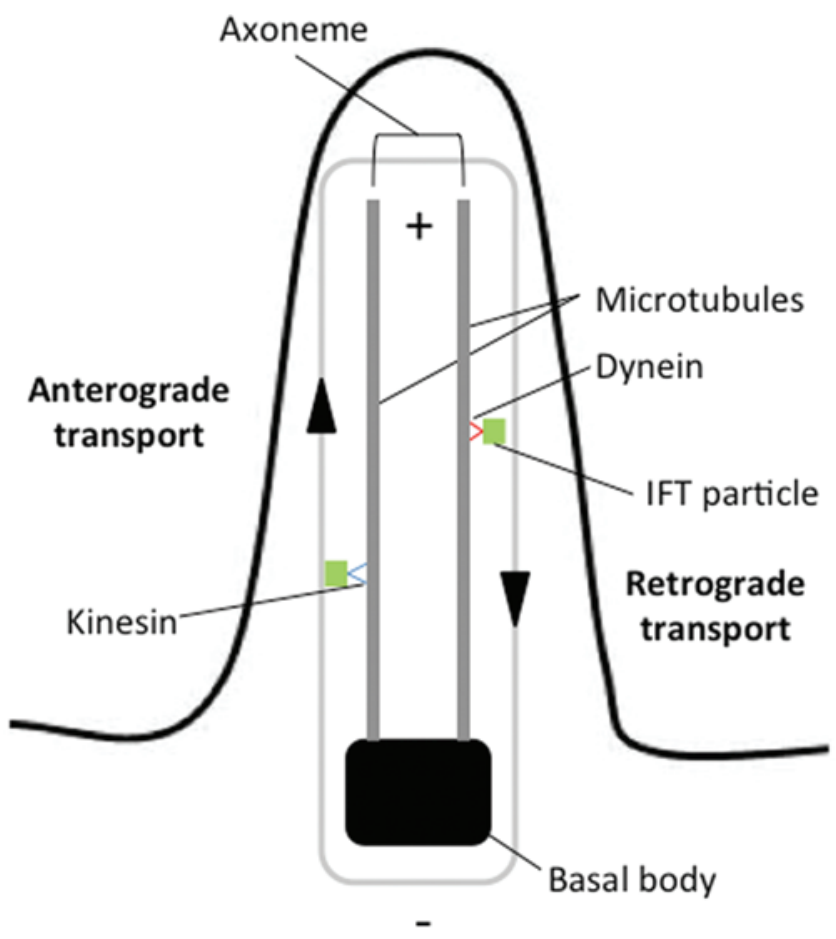

Fıg. 1. Intraflagellar transport. Cilia are hairlike structures that require transport proteins to function normally. Kinesin and dynein carry cargo proteins via interactions with intraflagellar transport (IFT) particles. These 2 transport proteins "walk" on ciliary axonemes (composed of microtubules) to mediate transport of cargo to the tip of the cilium (anterograde transport, + end, kinesin-mediated) and from the tip of the cilium to the basal body (retrograde transport, - end, dynein-mediated). Based on Goetz and Anderson. ${ }^{20}$ from the cell surface and serve as signaling centers for various developmental pathways..$^{20}$ Primary cilia result from interphase of the cell cycle and develop from a mother centriole that fuses with the plasma membrane and gives rise to the microtubule-based axoneme..$^{49}$ The cilia are anchored by a basal body where proteins and protein complexes are recruited to the developing cilium..$^{36}$ There is a dynamic interaction with surrounding element $\mathrm{s}^{39}$ that regulates protein ingress and egress to the cilia in a process known as intraflagellar transport. ${ }^{18}$ Intraflagellar transport allows bidirectional movement of proteins and protein complexes to the distal tip of the cilia for microtubule maintenance, assembly, and signaling. ${ }^{50}$ These same processes occur when material is carried back toward the cell body (Fig. 1). Until recently, primary cilia were not thought to play essential roles in cellular function; however, further investigations have revealed that the flux of material in and out of the cilia plays essential roles in chemosensation ${ }^{20}$ and signaling cascades. ${ }^{17}$ As discussed below, primary cilia are also essential for neural tube patterning. ${ }^{29,64}$

\section{Signaling in Neural Tube Development}

Normal patterning of the dorsal and ventral neural tube results from complex interactions in signaling cascades and concerted changes in cell fate and migration. ${ }^{47}$ Cell fate, the process of cell differentiation to a specific cell type, is determined by the transcriptional regulation of genes, while cell movement relies on signals regulating cytoskeletal components. In vertebrates, neural tube development starts with the flattened neural plate, a thickening of the dorsal ectoderm overlying the mesoderm. ${ }^{34}$ The neural plate is induced to roll onto itself during neurulation, forming neural crests that then fuse to form the neural tube structure, while the underlying mesoderm also involutes to form the notochord. Closure of the neural tube begins at the boundary near the craniocervical junction and precedes rostrally to the forebrain and caudally along the spine. ${ }^{52}$ The closure of the brain ends in the cranial neuropore, and the spine closure ends in the caudal neuropore. ${ }^{7}$ Dorsal and ventral patterning then follows and leads to the development of the roof plate along the dorsal neural tube and the floor plate along the ventral neural tube ${ }^{29}$ (Fig. 2). Polarization continues with the development of motor and sensory neurons.

Patterning, differentiation, closure, polarity, fusion, and cell migration in the neural tube are closely regulated by several signaling cascades related to primary cilia. Normal neural tube development ${ }^{67}$ relies on efficient and rapid interaction between protein receptors and complexes. Clustering of this machinery to a highly regulated subcellular location such as primary cilia promotes such resourceful communication between signaling pathways. ${ }^{60}$ The enrichment of proteins in different parts of the cilia is also tightly regulated during development.

\section{Hedgehog Signaling}

Neural tube development results from the orchestration of signaling pathways such as the hedgehog $(\mathrm{Hh})$ pathway. ${ }^{11}$ The Hh pathway relies on the integrity of the primary cilium for signal transduction. Hh proteins and 


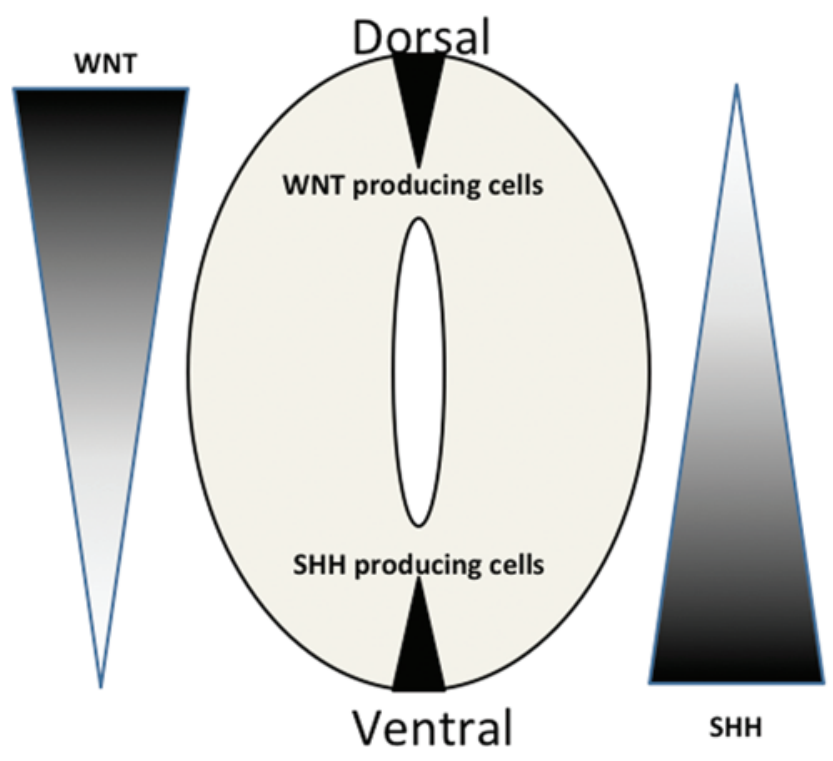

Fig. 2. Dorsal-ventral Wnt and Shh gradients in the developing neural tube. Wnt-producing cells are located in dorsal regions and Shhproducing cells are confined to the ventral regions of the neural tube creating a dorsal-ventral gradient with Wnt being expressed at high levels dorsally and Shh being expressed at high levels ventrally. Wht and Shh act to regulate one another's expression in a negative feedback system. SHH = Shh; WNT = Wnt.

their complexes are localized to the primary cilium either at rest or following activation. During development the notochord generates a gradient of Sonic hedgehog (Shh) to specify the ventral neural tube and regulate neural progenitor development. ${ }^{24} \mathrm{Shh}$ is a morphogen that acts in a concentration-dependent manner to regulate cell fate. Shh is first expressed in the notochord and later expression arises from the floor plate of the ventral neural tube (Fig. 2). Normal dorsal-ventral patterning of the neural tube relies on Shh expression and its interactions with other ciliary proteins. ${ }^{47}$

One set of ciliary proteins crucial for neural tube development is the glioma-associated oncogene homolog (Gli) family members that are zinc-finger transcription factors involved in Hh signaling during embryogenesis. ${ }^{30}$ The Hh pathway regulates posttranslational modification of Gli proteins and regulates their transcriptional activity. In turn, Gli proteins act as both transcriptional activators and repressors of the Hh pathway. ${ }^{47}$ In mammalian cells during development, the binding of $\mathrm{Hh}$ to its receptor patched (Ptch) in the cell membrane inactivates the receptor and releases inhibition of smoothened (Smo), a transmembrane protein. Hh binding to Ptch promotes localization of Smo to primary cilia, and facilitates downstream signaling with Gli proteins relocating to the tips of primary cilia following pathway activation. ${ }^{48}$ Gli function is dependent upon intraflagellar transport for its translocation and function. Without activation, Ptch resides in primary cilia and prevents or limits the localization of Smo. The activation of Smo is, therefore, dependent upon the primary cilia. With Smo activated and present at the tip of the primary cilium, Gli and other transcription regulators can act on their downstream targets for neural tube patterning ${ }^{15,30}$ (Fig. 3A).
Shh regulates Gli and other transcription factors through multiple feedback loops during ventral neural tube patterning. Shh regulates gene expression by restricting dorsally expressed genes and inducing ventrally expressed transcription factors. The resulting Gli gradient regulates ventral neural tube development, and mutations in these proteins lead to abnormal neural progenitor populations..$^{30}$ The same Shh-dependent mechanisms can be seen in the developing midbrain.

\section{Wnt Signaling}

Recent evidence in Wnt signaling is beginning to explain the molecular mechanisms modifying failure of neural tube closure. While Shh expression is limited to a ventral location in the developing neural tube, Wnt expression occurs along the dorsal aspect, regulating neural crest development and patterning of the cells at this location where clinical phenotypes are observed. Along with bone morphogenic proteins, Wnt antagonizes Shh signaling to regulate neural progenitor differentiation at the roof plate. ${ }^{27} \mathrm{Wnt}$ signaling regulates Shh pathways by using, among other ciliary complexes, the Gli proteins to repress Shh expression along the dorsal regions of the neural tube. ${ }^{68}$

Wnt proteins are secreted signaling proteins whose functions are largely dependent upon the receptor bound and the cell type targeted during neural development. ${ }^{60}$ The canonical Wnt pathway is a signaling pathway that involves downstream activation of $\beta$-catenin after Wnt ligands bind to a cell-surface receptor in the frizzled (Frz) family. Binding of Wnt to Frz activates a set of dishevelled (Dsh) proteins that function through inhibition of an Axin-Gsk3-APC pathway to prevent degradation of $\beta$-catenin as an intracellular signaling molecule. ${ }^{15}$ Betacatenin then upregulates various transcription factors to promote specific gene expression (Fig. 3C). While the integration of Shh and primary cilia function is well established, the relationship between primary cilia function and Wnt signaling is not as well understood and is an area of ongoing inquiry. There are indications that primary cilia inhibit the canonical Wnt pathway during development and that this signaling cascade is critical for normal CNS patterning. ${ }^{40}$ Further investigation into the role of primary cilia and its influence on Wnt signaling during development is ongoing. ${ }^{14}$

The planar cell polarity (PCP) pathway involving Wnt signaling is also a well-established signaling cascade influencing neural tube development, and its interaction with primary cilia ${ }^{43}$ is an area of significant genetic interest. ${ }^{31}$ The PCP pathway is considered a noncanonical Wnt pathway and does not involve activation of $\beta$-catenin. ${ }^{54}$ The PCP pathway regulates the canonical pathway and is involved in patterning and cell orientation. PCP was first identified independent of its role in Wnt signaling; however, as mutant mouse models were developed with genetic knockout of various PCP partners, NTDs were found in the animals, ${ }^{21}$ suggesting Wnt's role in dorsal neural tube development. ${ }^{11}$

The PCP pathway is activated by binding of extracellular Wnt to protein receptors such as Frz that associate with the intracellular protein Dsh. There are other trans- 
T. W. Vogel et al.
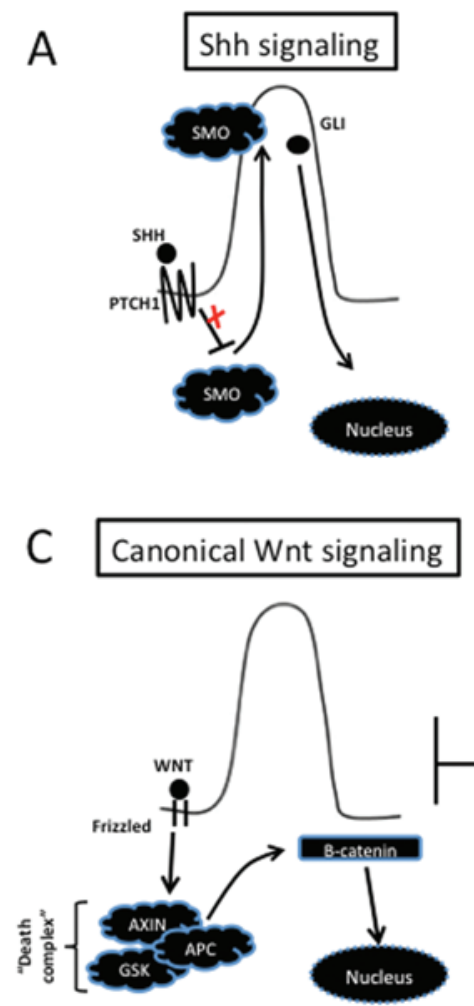

B PDGFR $\alpha$ signaling

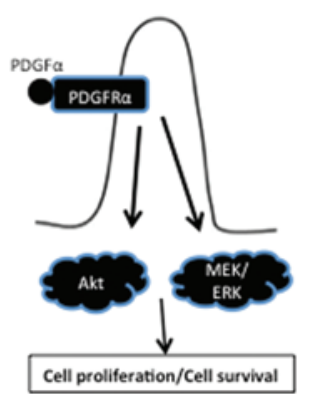

D

Non-canonical Wnt (PCP) signaling

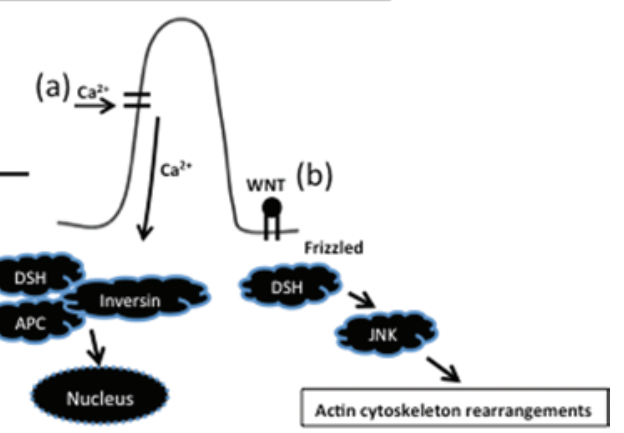

FIG. 3. Ciliary facilitation of cellular signaling. A: Shh signaling: Shh binds to its receptor, Ptch1. In the absence of Shh, Ptch1 inhibits Smo. Once Shh binds to Ptch1, Ptch1 inhibition of Smo is removed, and Smo is activated, translocating to the cilium, where it activates Gli transcription factors. These transcription factors translocate to the nucleus and modify gene expression. B: PDGFR $\alpha$ signaling: PDGF $\alpha$ activates the receptor, triggering the activation of downstream signaling proteins Akt and MEK/ERK, which promotes cell proliferation and cell survival. C C: Wnt signaling: Wnt binds to its receptor, Frz (frizzled), leading to inhibition of the "death complex" (Axin, GSK [glycogen synthase kinase], and APC). This results in an increase in the intracellular levels of $\beta$-catenin, which translocates to the nucleus and alters gene expression. $\mathbf{D}$ : Noncanonical Wnt $/ \mathrm{Ca}^{2+}$ signaling (a): Intracellular $\mathrm{Ca}^{2+}$ release increases expression of inversin, which causes degradation of cytoplasmic Dsh through an APCdependent mechanism, making it unavailable for canonical WNT signaling (inhibiting canonical WNT signaling). PCP signaling (b): Wnt binding to Frz activates Dsh, triggering activation of JNK, leading to modification of the actin cytoskeleton. Akt $=$ protein kinase B; AXIN = Axin; MEK/ERK = mitogen activated protein kinase signaling pathway; $\mathrm{PTCH} 1=\mathrm{Ptch} 1 ; \mathrm{SMO}=\mathrm{Smo}$. Based

membrane proteins, notably Flamingo (Celsr) and Vangl, which associate with cytoplasmic protein complexes such as prickle. Binding of Wnt ligands leads to activation of the downstream MAPK-JNK and RHO-RAC pathways to influence transcriptional regulation ${ }^{59}$ (Fig. 3D). The transmembrane protein complexes in the PCP pathway accumulate in an asymmetrical manner and establish polarized cell-cell communication ${ }^{31}$ during critical steps in neural development. Neural tube closure is sensitive to loss of function in the PCP pathway, ${ }^{75}$ which leads to adverse effects on neurulation and differentiation of neural progenitors. ${ }^{52}$ The PCP pathway acts upstream of ciliogenesis and regulates the position of basal bodies and cell orientation. ${ }^{64}$ Alterations in PCP signaling in cilia manifest with CNS phenotypes in ependymal cells, ${ }^{22}$ where the function and morphology of motile cilia are adversely affected, leading to lethal hydrocephalus. ${ }^{65}$

\section{PDGF Signaling}

Platelet-derived growth factor is another pathway that is required for normal neural development in the brain and spinal cord. Oligodendrocytic differentiation and migration as well as neural tube closure are dependent upon this pathway's function. PDGF binds to its receptor, PDGFR, and both the ligand and receptors have homodimers and heterodimers that activate downstream PI3K-AKT and the MEK1-ERK1 pathways ${ }^{15}$ regulating cell proliferation and cell death (Fig. 3B). PDGFRs are localized to and upregulated in cilia and have been shown to be essential in oligodendrocytic precursor cell migration $^{35}$ in the spinal cord ${ }^{66}$ and brain, and PDGFRknockout mice have NTDs. ${ }^{61}$ Primary cilia transduce PDGF signaling, and investigators are exploring the role of this cascade to determine if it is involved in neuron migration. ${ }^{40}$

\section{Ciliopathies as Models of NTDs}

There are more than a dozen ciliopathies that have been described in the genetics literature each with a set of genes associated with varying systemic presentations. ${ }^{49}$ The uniting principle behind these disorders, however, is their dysregulation of cilia-related proteins. There are 2 main ciliopathies that are associated with NTDs (Table 1). 


\section{Cilia and neural tube defects}

TABLE 1: Ciliopathies commonly associated with NTDs

\begin{tabular}{cccc}
\hline Ciliopathy & Known Genes & NTD & Systemic Phenotype \\
\hline $\begin{array}{c}\text { Meckel-Gruber } \\
\text { syndrome }\end{array}$ & MKS1-6 & occipital encephalocele & $\begin{array}{c}\text { polycystic kidney disease, polydactyly, hydrocephalus, Dandy-Walker } \\
\text { malformation }\end{array}$ \\
Joubert syndrome & NPHP3, NPHP6, NPHP8, & encephalocele & mental retardation, vermian hypoplasia, midbrain malformation, retinal \\
& AHI1, MKS3, ARL13B, \\
& INPP5E, TMEM216, NPHP1 & \\
\hline
\end{tabular}

\section{Meckel-Gruber Syndrome}

Meckel-Gruber syndrome is the most common ciliopathy associated with occipital encephaloceles and meningoceles as NTDs. ${ }^{46}$ The estimated incidence of MKS is 1 in 3000 births, ${ }^{38}$ and the condition is characterized by polydactyly and renal cystic dysplasia, as well as several CNS phenotypes such as Dandy-Walker malformation, anencephaly, arhinencephaly, holoprosencephaly, and hydrocephalus. ${ }^{63}$ Meckel-Gruber syndrome is a neonatal lethal pleiotropic autosomal recessive disorder with NTDs resulting from abnormal signaling in primary cilia. ${ }^{38}$ In MKS patients, NTDs may be diagnosed prenatally through ultrasound investigations, MRI, and elevated alpha-fetoprotein levels. ${ }^{57}$

The pleiotropic phenotypes for MKS patients may result from the different $M K S$ genes that are mutated. The MKS1 protein and its interacting proteins localize to the base of the cilium and are often found in other ciliopathies. MKS1 is frequently mutated in MKS patients with occipital encephaloceles, with approximately $90 \%$ of affected MKS neonates presenting with this NTD. ${ }^{55}$ In mouse models, loss of $M k s 1$ or other $M k s$ gene function alters neural tube patterning, resulting in exencephaly, a severe NTD in mice. ${ }^{12}$ Mks 1 interacts with members of the tectonic family, transmembrane proteins that work through Hh pathways to pattern the neural tube in mice. ${ }^{56}$ Altered Hh pathways are also seen in similar defects in human MKS patients. ${ }^{72} M K S 1$ also interacts with MKS6, and MKS6 mutations are associated with human NTDs. ${ }^{46,63}$ Mutations in $M K S 5$, a ciliary gene whose protein product localizes to basal bodies and centrosomes and forms protein complexes with other essential ciliary proteins, are associated with occipital encephaloceles in fetuses..$^{12}$ Mutations in the various $M K S$ genes,${ }^{13}$ therefore, lead to abnormalities in proteins localized to primary cilia. ${ }^{8}$ MKS proteins are involved in human Hh signaling and are essential for cilia structure and function in maintaining normal neural tube patterning.

\section{Joubert Syndrome}

Joubert syndrome ${ }^{57}$ is an autosomal recessive ciliopathy with an estimated prevalence of 1 in 100,000 patients. Patients affected by this disorder present with a variety of phenotypes including hypotonia, hypoplasia of the cerebellum, mental retardation, and abnormal breathing patterns in infancy. ${ }^{49,57}$ Presence of a molar-tooth sign-a widened interpeduncular fossa, thickened superior cerebellar peduncles, and vermian hypoplasia-on MR images is pathognomonic for JBTS. ${ }^{70}$ In addition to these
CNS-related phenotypes, JBTS patients may present with NTDs, including occipital encephaloceles..$^{33,69}$

The genes associated with JBTS localize to the cilium and the basal body. ${ }^{14}$ There is phenotypic overlap seen in MKS and JBTS ${ }^{56}$ which may result from phenocopies; mutations in 2 different genes presenting with the same phenotype; allelic diversity, in which an affected allele can present with different phenotypes; or modifier genes that regulate or interact with an affected allele and modify its phenotypic expressivity. ${ }^{49}$ The neurological defects seen in JBTS patients do not appear to be degenerative or progressive, and encephaloceles, if they occur with mild presentation, may be repaired with surgery. ${ }^{37}$

\section{Discussion}

Neural tube defects have gained significant attention in the last several years, with the progress made in fetal treatment for selected patients with spina bifida. ${ }^{4}$ As a result of these reports, the prevention and treatment ${ }^{9}$ of these disorders is a growing area of research. ${ }^{74}$ In addition to the therapeutic advances made by neurosurgeons in the fetal treatment of spina bifida, there has been a growing focus on folate supplementation in developing countries, ${ }^{77}$ where access to financial resources and health care is limited. Folate deficiency has been implicated in the genesis of certain NTDs, ${ }^{77}$ and the story is one of success in the medical community's ability to achieve results with preventative measures. ${ }^{10}$ Genetic studies ${ }^{45}$ have recently been coupled with this focus on environmental factors ${ }^{51}$ and have yielded insight into the various signaling cascades and genes ${ }^{3}$ necessary for normal neural tube development.

There are several forms of NTDs that are commonly seen in human development and are classified primarily by the level of the CNS that is affected. Anencephaly refers to a defect resulting from failure of closure in the forebrain and midbrain. Craniorachischisis, the most severe NTD, originates from failure of fusion in the areas of both the hindbrain and spinal cord. Spina bifida is the most common NTD and is compatible with postnatal survival; the condition results from partial failure of spinal neural tube closure, usually in the lumbosacral region. ${ }^{71}$ Closed forms of NTDs are also seen with encephaloceles and meningoceles (Fig. 4). Genetic knockouts in mice have attempted to model these varying diseases and the anatomical level of neural tube abnormality. Mouse models utilizing PCP-related genes have identified NTDs resulting from abnormal fusion in the spinal cord and hindbrain, suggesting that these are models for cranio- 

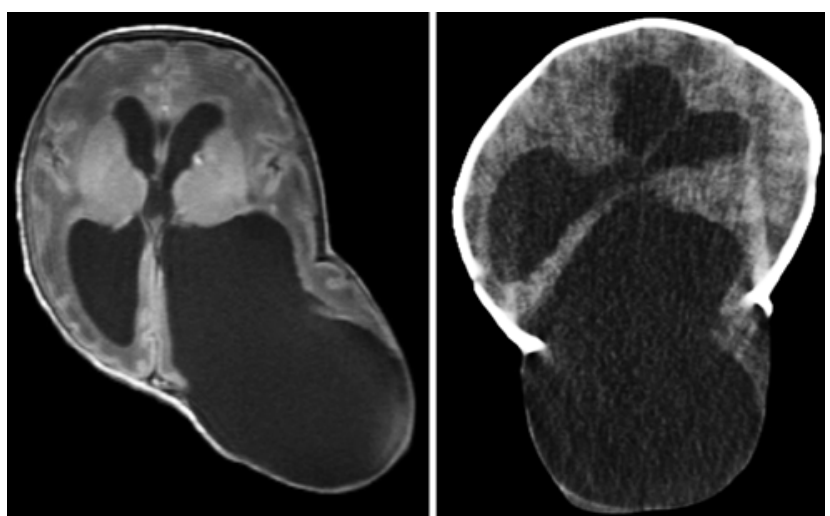

Fig. 4. Parietooccipital encephalocele-an example of a closed NTD in in a newborn. A: Axial noncontrast MRI revealing a parietooccipital encephalocele with continuity with the ventricular system. B: Axial noncontrast CT scan obtained in the same patient revealing the underlying absence of bone fusion, resulting in a closed NTD.

rachischisis. ${ }^{25}$ Several other mouse models have identified mutations in proteins required for ciliogenesis and in intraflagellar transport. These mouse models can be used to understand cilia and their essential role in neural tube closure in the cranial and spinal regions.

There is also genetic evidence in human patients with NTDs that primary cilia and the proteins responsible for ciliogenesis play a critical role in cranial and spinal neural development. Both MKS and JBTS are frequently associated with closed forms of NTDs. Studies on open forms of NTDs ${ }^{41}$ may be limited by small patient cohorts; however, recent multi-institutional studies ${ }^{42}$ have sought to pool patient sample data to aid in candidate gene identification in spina bifida. ${ }^{6}$ In addition to the MKS and JBTS ciliopathies, there are other ciliary proteins that are mutated in patients with CNS phenotypes resembling NTDs. ${ }^{40}$ Mutations in GLI2 are associated with human congenital malformations, including holoprosencepha$1 y,{ }^{25}$ and a recent study has identified GLI3 mutations in patients with features of the ciliopathy, oral-facial-digital syndrome $^{30}$ (OFDS, MIM 311200). PCP genes such as CELSRI and SCRIBI have been implicated in human cases of craniorachischisis, suggesting a role of Wnt signaling in cilia-related NTDs. ${ }^{52}$ Additional work also has correlated PCP genes VANGL1, VANGL2, PRICKLE2, and $F U Z Z Y^{26}$ with human NTDs. ${ }^{58,73}$

While genetic mechanisms continue to expand our understanding of neural tube formation, there remain a large percentage of patients with NTDs in whom the etiology of the disease is poorly understood and the genetic contributions remain unclear. Patients presenting for neurosurgical evaluation for treatable forms of NTDs, including meningoceles, encephaloceles, and spina bifida, may provide insight into the evolving role of cilia in the genesis of these disorders. Mutational analysis for ciliaassociated genes or related primary-cilia signaling cascades will hopefully elucidate the contributions of these organelles with respect to human neural tube development and disease.

\section{Conclusions}

Most recently, fetal treatment of spina bifida has be- come a reality at specialized fetal care centers in the US. This evolving treatment strategy has brought renewed attention to the treatment, prevention, and genetic study of NTDs. While surgery for NTDs can improve outcomes in affected children, there is hope that understanding the genetic underpinnings of these disorders will lead to noninvasive methods of prevention and treatment. Identifying genetic risk factors is one step toward this goal. Primary cilia are quickly being recognized as major contributors to normal neural development and to the patterning of the neural tube. The Shh pathway is a well-established model implicating these organelles in human disease. Future work on the canonical Wnt and PCP pathways in primary cilia may yield additional insight into the developmental mechanisms underlying neural tube development.

\section{Disclosure}

The authors report no conflict of interest concerning the materials or methods used in this study or the findings specified in this paper.

Author contributions to the study and manuscript preparation include the following. Conception and design: Vogel, Carter. Acquisition of data: Vogel, Carter, Abode-Iyamah. Analysis and interpretation of data: all authors. Drafting the article: Vogel. Critically revising the article: all authors. Reviewed submitted version of manuscript: all authors. Approved the final version of the manuscript on behalf of all authors: Vogel. Administrative/technical/material support: Robinson.

\section{References}

1. Badano JL, Katsanis N: Life without centrioles: cilia in the spotlight. Cell 125:1228-1230, 2006

2. Banizs B, Pike MM, Millican CL, Ferguson WB, Komlosi P, Sheetz J, et al: Dysfunctional cilia lead to altered ependyma and choroid plexus function, and result in the formation of hydrocephalus. Development 132:5329-5339, 2005

3. Bassuk AG, Kibar Z: Genetic basis of neural tube defects. Semin Pediatr Neurol 16:101-110, 2009

4. Bauer SB: Prenatal versus postnatal repair of myelomeningocele. N Engl J Med 364:2554-2556, 2011 (Letter)

5. Blom HJ: Folic acid, methylation and neural tube closure in humans. Birth Defects Res A Clin Mol Teratol 85:295-302, 2009

6. Carter TC, Pangilinan F, Troendle JF, Molloy AM, VanderMeer J, Mitchell A, et al: Evaluation of 64 candidate single nucleotide polymorphisms as risk factors for neural tube defects in a large Irish study population. Am J Med Genet A 155A:14-21, 2011

7. Copp AJ, Greene ND: Genetics and development of neural tube defects. J Pathol 220:217-230, 2010

8. Cui C, Chatterjee B, Francis D, Yu Q, SanAgustin JT, Francis $\mathrm{R}$, et al: Disruption of Mks1 localization to the mother centriole causes cilia defects and developmental malformations in Meckel-Gruber syndrome. Dis Model Mech 4:43-56, 2011

9. Czeizel AE, Dudás I: Prevention of the first occurrence of neural-tube defects by periconceptional vitamin supplementation. N Engl J Med 327:1832-1835, 1992

10. De-Regil LM, Fernández-Gaxiola AC, Dowswell T, Peña-Rosas JP: Effects and safety of periconceptional folate supplementation for preventing birth defects. Cochrane Database System Rev (10):CD007950, 2010

11. Delaunay D, Heydon K, Cumano A, Schwab MH, Thomas JL, Suter U, et al: Early neuronal and glial fate restriction of embryonic neural stem cells. J Neurosci 28:2551-2562, 2008

12. Delous M, Baala L, Salomon R, Laclef C, Vierkotten J, Tory 
$\mathrm{K}$, et al: The ciliary gene RPGRIP1L is mutated in cerebellooculo-renal syndrome (Joubert syndrome type B) and Meckel syndrome. Nat Genet 39:875-881, 2007

13. Dowdle WE, Robinson JF, Kneist A, Sirerol-Piquer MS, Frints SG, Corbit KC, et al: Disruption of a ciliary B9 protein complex causes Meckel syndrome. Am J Hum Genet 89:94-110, 2011 (Erratum in Am J Hum Genet 89:589, 2011)

14. Duldulao NA, Li J, Sun Z: Cilia in cell signaling and human disorders. Protein Cell 1:726-736, 2010

15. Eggenschwiler JT, Anderson KV: Cilia and developmental signaling. Annu Rev Cell Dev Biol 23:345-373, 2007

16. Fliegauf M, Benzing T, Omran H: When cilia go bad: cilia defects and ciliopathies. Nat Rev Mol Cell Biol 8:880-893, 2007

17. Garcia-Gonzalo FR, Corbit KC, Sirerol-Piquer MS, Ramaswami G, Otto EA, Noriega TR, et al: A transition zone complex regulates mammalian ciliogenesis and ciliary membrane composition. Nat Genet 43:776-784, 2011

18. Gascue C, Tan PL, Cardenas-Rodriguez M, Libisch G, Fernandez-Calero T, Liu YP, et al: Direct role of Bardet-Biedl syndrome proteins in transcriptional regulation. J Cell Sci 125: 362-375, 2012

19. Gavino C, Richard S: Patched1 haploinsufficiency impairs ependymal cilia function of the quaking viable mice, leading to fatal hydrocephalus. Mol Cell Neurosci 47:100-107, 2011

20. Goetz SC, Anderson KV: The primary cilium: a signalling centre during vertebrate development. Nat Rev Genet 11:331-344, 2010

21. Gray RS, Abitua PB, Wlodarczyk BJ, Szabo-Rogers HL, Blanchard O, Lee I, et al: The planar cell polarity effector Fuz is essential for targeted membrane trafficking, ciliogenesis and mouse embryonic development. Nat Cell Biol 11:1225-1232, 2009

22. Guirao B, Meunier A, Mortaud S, Aguilar A, Corsi JM, Strehl $\mathrm{L}$, et al: Coupling between hydrodynamic forces and planar cell polarity orients mammalian motile cilia. Nat Cell Biol 12:341350,2010

23. Han YG, Kim HJ, Dlugosz AA, Ellison DW, Gilbertson RJ, Alvarez-Buylla A: Dual and opposing roles of primary cilia in medulloblastoma development. Nat Med 15:1062-1065, 2009

24. Han YG, Spassky N, Romaguera-Ros M, Garcia-Verdugo JM, Aguilar A, Schneider-Maunoury S, et al: Hedgehog signaling and primary cilia are required for the formation of adult neural stem cells. Nat Neurosci 11:277-284, 2008

25. Harris MJ, Juriloff DM: An update to the list of mouse mutants with neural tube closure defects and advances toward a complete genetic perspective of neural tube closure. Birth Defects Res A Clin Mol Teratol 88:653-669, 2010

26. Heydeck W, Liu A: PCP effector proteins inturned and fuzzy play nonredundant roles in the patterning but not convergent extension of mammalian neural tube. Dev Dyn 240:19381948, 2011

27. Heydeck W, Zeng H, Liu A: Planar cell polarity effector gene Fuzzy regulates cilia formation and Hedgehog signal transduction in mouse. Dev Dyn 238:3035-3042, 2009

28. Hildebrandt F, Benzing T, Katsanis N: Ciliopathies. N Engl J Med 364:1533-1543, 2011

29. Horner VL, Caspary T: Disrupted dorsal neural tube BMP signaling in the cilia mutant Arl $13 \mathrm{~b}$ hnn stems from abnormal Shh signaling. Dev Biol 355:43-54, 2011

30. Hui CC, Angers S: Gli proteins in development and disease. Annu Rev Cell Dev Biol 27:513-537, 2011

31. Jones C, Roper VC, Foucher I, Qian D, Banizs B, Petit C, et al: Ciliary proteins link basal body polarization to planar cell polarity regulation. Nat Genet 40:69-77, 2008

32. Katsanis N: Ciliary proteins and exencephaly. Nat Genet 38: 135-136, 2006

33. Keeler LC, Marsh SE, Leeflang EP, Woods CG, Sztriha L, AlGazali L, et al: Linkage analysis in families with Joubert syn- drome plus oculo-renal involvement identifies the CORS2 locus on chromosome 11p12-q13.3. Am J Hum Genet 73:656-662, 2003

34. Kibar Z, Capra V, Gros P: Toward understanding the genetic basis of neural tube defects. Clin Genet 71:295-310, 2007

35. Klinghoffer RA, Hamilton TG, Hoch R, Soriano P: An allelic series at the PDGFalphaR locus indicates unequal contributions of distinct signaling pathways during development. Dev Cell 2:103-113, 2002

36. Lee JE, Silhavy JL, Zaki MS, Schroth J, Bielas SL, Marsh SE, et al: CEP41 is mutated in Joubert syndrome and is required for tubulin glutamylation at the cilium. Nat Genet 44:193199, 2012

37. Lo BWY, Kulkarni AV, Rutka JT, Jea A, Drake JM, LambertiPasculli M, et al: Clinical predictors of developmental outcome in patients with cephaloceles. Clinical article. J Neurosurg Pediatr 2:254-257, 2008

38. Logan CV, Abdel-Hamed Z, Johnson CA: Molecular genetics and pathogenic mechanisms for the severe ciliopathies: insights into neurodevelopment and pathogenesis of neural tube defects. Mol Neurobiol 43:12-26, 2011

39. Loktev AV, Zhang Q, Beck JS, Searby CC, Scheetz TE, Bazan JF, et al: A BBSome subunit links ciliogenesis, microtubule stability, and acetylation. Dev Cell 15:854-865, 2008

40. Louvi A, Grove EA: Cilia in the CNS: the quiet organelle claims center stage. Neuron 69:1046-1060, 2011

41. Marini NJ, Hoffmann TJ, Lammer EJ, Hardin J, Lazaruk K, Stein JB, et al: A genetic signature of spina bifida risk from pathway-informed comprehensive gene-variant analysis. PLoS ONE 6:e28408, 2011

42. Martinez CA, Northrup H, Lin JI, Morrison AC, Fletcher JM, Tyerman GH, et al: Genetic association study of putative functional single nucleotide polymorphisms of genes in folate metabolism and spina bifida. Am J Obstet Gynecol 201: 394.e1-394.e11, 2009

43. Mirzadeh Z, Han YG, Soriano-Navarro M, García-Verdugo JM, Alvarez-Buylla A: Cilia organize ependymal planar polarity. J Neurosci 30:2600-2610, 2010

44. Mirzadeh Z, Merkle FT, Soriano-Navarro M, Garcia-Verdugo JM, Alvarez-Buylla A: Neural stem cells confer unique pinwheel architecture to the ventricular surface in neurogenic regions of the adult brain. Cell Stem Cell 3:265-278, 2008

45. Molloy AM, Brody LC, Mills JL, Scott JM, Kirke PN: The search for genetic polymorphisms in the homocysteine/folate pathway that contribute to the etiology of human neural tube defects. Birth Defects Res A Clin Mol Teratol 85:285-294, 2009

46. Mougou-Zerelli S, Thomas S, Szenker E, Audollent S, Elkhartoufi N, Babarit C, et al: CC2D2A mutations in Meckel and Joubert syndromes indicate a genotype-phenotype correlation. Hum Mutat 30:1574-1582, 2009

47. Murdoch JN, Copp AJ: The relationship between sonic Hedgehog signaling, cilia, and neural tube defects. Birth Defects Res A Clin Mol Teratol 88:633-652, 2010

48. Norman RX, Ko HW, Huang V, Eun CM, Abler LL, Zhang Z, et al: Tubby-like protein 3 (TULP3) regulates patterning in the mouse embryo through inhibition of Hedgehog signaling. Hum Mol Genet 18:1740-1754, 2009

49. Novarino G, Akizu N, Gleeson JG: Modeling human disease in humans: the ciliopathies. Cell 147:70-79, 2011

50. Parker DS, Katsanis N: Understanding cargo specificity in intraflagellar transport. EMBO J 30:2518-2519, 2011

51. Ren A, Qiu X, Jin L, Ma J, Li Z, Zhang L, et al: Association of selected persistent organic pollutants in the placenta with the risk of neural tube defects. Proc Natl Acad Sci U S A 108: 12770-12775, 2011

52. Robinson A, Escuin S, Doudney K, Vekemans M, Stevenson RE, Greene NDE, et al: Mutations in the planar cell polarity genes CELSR1 and SCRIB are associated with the severe 
neural tube defect craniorachischisis. Hum Mutat 33:440447, 2012

53. Rogers SW, Tvrdik P, Capecchi MR, Gahring LC: Prenatal ablation of nicotinic receptor alpha7 cell lineages produces lumbosacral spina bifida the severity of which is modified by choline and nicotine exposure. Am J Med Genet A 158A:1135-1144, 2012

54. Ross AJ, May-Simera H, Eichers ER, Kai M, Hill J, Jagger DJ, et al: Disruption of Bardet-Biedl syndrome ciliary proteins perturbs planar cell polarity in vertebrates. Nat Genet 37: 1135-1140, 2005

55. Salonen R, Norio R: The Meckel syndrome in Finland: epidemiologic and genetic aspects. Am J Med Genet 18:691-698, 1984

56. Sang L, Miller JJ, Corbit KC, Giles RH, Brauer MJ, Otto EA, et al: Mapping the NPHP-JBTS-MKS protein network reveals ciliopathy disease genes and pathways. Cell 145:513-528, 2011

57. Sattar S, Gleeson JG: The ciliopathies in neuronal development: a clinical approach to investigation of Joubert syndrome and Joubert syndrome-related disorders. Dev Med Child Neurol 53:793-798, 2011

58. Seo JH, Zilber Y, Babayeva S, Liu J, Kyriakopoulos P, De Marco P, et al: Mutations in the planar cell polarity gene, Fuzzy, are associated with neural tube defects in humans. Hum Mol Genet 20:4324-4333, 2011

59. Simons M, Mlodzik M: Planar cell polarity signaling: from fly development to human disease. Annu Rev Genet 42:517540, 2008

60. Singla V, Reiter JF: The primary cilium as the cell's antenna: signaling at a sensory organelle. Science 313:629-633, 2006

61. Soriano P: The PDGF alpha receptor is required for neural crest cell development and for normal patterning of the somites. Development 124:2691-2700, 1997

62. Spassky N, Han YG, Aguilar A, Strehl L, Besse L, Laclef C, et al: Primary cilia are required for cerebellar development and Shh-dependent expansion of progenitor pool. Dev Biol 317: 246-259, 2008

63. Tallila J, Jakkula E, Peltonen L, Salonen R, Kestilä M: Identification of CC2D2A as a Meckel syndrome gene adds an important piece to the ciliopathy puzzle. Am J Hum Genet 82: 1361-1367, 2008

64. Tissir F, Goffinet AM: Planar cell polarity signaling in neural development. Curr Opin Neurobiol 20:572-577, 2010

65. Tissir F, Qu Y, Montcouquiol M, Zhou L, Komatsu K, Shi D, et al: Lack of cadherins Celsr2 and Celsr3 impairs ependymal ciliogenesis, leading to fatal hydrocephalus. Nat Neurosci 13: 700-707, 2010

66. Toepoel M, Steegers-Theunissen RPM, Ouborg NJ, Franke B, González-Zuloeta Ladd AM, Joosten PHLJ, et al: Interaction of PDGFRA promoter haplotypes and maternal environmen- tal exposures in the risk of spina bifida. Birth Defects Res A Clin Mol Teratol 85:629-636, 2009

67. Tu CT, Yang TC, Huang HY, Tsai HJ: Zebrafish arl6ip1 is required for neural crest development during embryogenesis. PLOS ONE 7:e32899, 2012

68. Tuson M, He M, Anderson KV: Protein kinase A acts at the basal body of the primary cilium to prevent Gli2 activation and ventralization of the mouse neural tube. Development 138: 4921-4930, 2011

69. Valente EM, Salpietro DC, Brancati F, Bertini E, Galluccio T, Tortorella G, et al: Description, nomenclature, and mapping of a novel cerebello-renal syndrome with the molar tooth malformation. Am J Hum Genet 73:663-670, 2003

70. Vogel TW, Dlouhy BJ, Menezes AH: Craniovertebral junction abnormality in a case of Joubert syndrome. Childs Nerv Syst 28:1109-1112, 2012

71. Wallingford JB: Planar cell polarity, ciliogenesis and neural tube defects. Hum Mol Genet 15 (Spec No 2):R227-R234, 2006

72. Weatherbee SD, Niswander LA, Anderson KV: A mouse model for Meckel syndrome reveals Mks1 is required for ciliogenesis and Hedgehog signaling. Hum Mol Genet 18:4565-4575, 2009

73. Wen S, Zhu H, Lu W, Mitchell LE, Shaw GM, Lammer EJ, et al: Planar cell polarity pathway genes and risk for spina bifida. Am J Med Genet A 152A:299-304, 2010

74. Wolff T, Witkop CT, Miller T, Syed SB: Folic acid supplementation for the prevention of neural tube defects: an update of the evidence for the US Preventive Services Task Force. Ann Intern Med 150:632-639, 2009

75. Zeng H, Hoover AN, Liu A: PCP effector gene Inturned is an important regulator of cilia formation and embryonic development in mammals. Dev Biol 339:418-428, 2010

76. Zhang Q, Nishimura D, Seo S, Vogel T, Morgan DA, Searby $\mathrm{C}$, et al: Bardet-Biedl syndrome 3 (Bbs3) knockout mouse model reveals common BBS-associated phenotypes and Bbs3 unique phenotypes. Proc Natl Acad Sci U S A 108:2067820683, 2011

77. Zhao W, Mosley BS, Cleves MA, Melnyk S, James SJ, Hobbs CA: Neural tube defects and maternal biomarkers of folate, homocysteine, and glutathione metabolism. Birth Defects Res A Clin Mol Teratol 76:230-236, 2006

Manuscript submitted June 1, 2012.

Accepted June 18, 2012.

Please include this information when citing this paper: DOI: 10.3171/2012.6.FOCUS12222.

Address correspondence to: Timothy W. Vogel, M.D., Washington University School of Medicine, Department of Pediatric Neurosurgery, St. Louis Children's Hospital, One Children's Place, Suite 4S20, St. Louis, Missouri 63110. email: vogelt@wudosis.wustl.edu. 